Research paper

\title{
Transferrin conjugates of antitubercular drug isoniazid: Synthesis and in vitro efficacy
}

\author{
Yogesh B. Sutar ${ }^{\text {a }}$, Jaishree K. Mali a, Vikas N. Telvekar ${ }^{\text {a, }}{ }^{*}$, Raju S. Rajmani ${ }^{\mathrm{b}}$, Amit Singh ${ }^{\mathrm{b}}$ \\ a Department of Pharmaceutical Sciences and Technology, Institute of Chemical Technology, Mumbai, 400 019, India \\ ${ }^{\mathrm{b}}$ Department of Microbiology and Cell Biology (MCBL), Centre for Infectious Disease Research (CIDR), Indian Institute of Science (IISc), Bangalore, 560 012, \\ India
}

\section{A R T I C L E I N F O}

\section{Article history:}

Received 30 April 2019

Received in revised form 24 June 2019

Accepted 16 September 2019

Available online 17 September 2019

Keywords:
Transferrin
Isoniazid
Conjugates
Mycobacterium tuberculosis
H37Rv

\begin{abstract}
A B S T R A C T
Tuberculosis (TB) caused by Mycobacterium tuberculosis (Mtb) has become the world's leading killer disease due to a single infectious agent which survives in the host macrophage for the indefinite period. Hence, it is necessary to enhance the efficacy of the clinically existing antitubercular agents or to discover new anti antitubercular agents. Here, we report the synthesis, characterization and antimycobacterial evaluation of protein-drug conjugates. A carrier protein, Transferrin (Tf) was covalently conjugated to isoniazid (INH) utilizing hydrazone and amide linkers. The purity of the reactions was confirmed by SDSPAGE while conjugation was confirmed by UV-visible spectrophotometry, MALDI-TOF analysis, and FTIR spectrophotometry. The in vitro antitubercular assay result showed that the inhibitory activity of the parent drug was conserved in both the conjugates. The conjugates were effective against intracellular $M t b$ H37Rv and were devoid of cytotoxic effect at therapeutic concentration.
\end{abstract}

(๑) 2019 Elsevier Masson SAS. All rights reserved.

\section{Introduction}

Tuberculosis (TB), caused by slow-growing intracellular actinomycete Mycobacterium tuberculosis (Mtb), has become the tenth leading cause of mortality in the world ranking above HIV/AIDs in infectious disease. According to the WHO survey, in 2017 there were 1.3 million TB deaths among HIV-negative people and as well 300000 deaths among HIV-positive people. In the year 2017 worldwide, 558000 people were found to be resistant to rifampicin (RR-TB), and $82 \%$ had multidrug-resistant TB (MDR-TB) out of which India, China, and the Russian Federation exhibited the most significant numbers of MDR/RR-TB incident cases [1]. The clinical manifestation of tuberculosis may be attributed to the fact that $M t b$ resides within the infected macrophages to either enter into a quiescent state for an indefinite period or disseminated to other body organs (rare) depending on the host immune response [2-4]. Although the clinical pipeline is flooded with new and repurposed anti-TB agents, TB continues to be a formidable public health challenge worldwide. The critical problem with the current tuberculosis chemotherapy is nontarget specificity resulting in adverse

\footnotetext{
* Corresponding author. Department of Pharmaceutical Sciences and Technology, Institute of Chemical Technology, Mumbai, 400 019, India.

E-mail address: vn.telvekar@ictmumbai.edu.in (V.N. Telvekar).
}

side effects [5]. Along with this, long duration of treatment, continuous and frequent multiple drug dosing causes noncompliance of patients to current therapy is a major contributory factor in the development of multidrug-resistant (MDR) tuberculosis and extensively drug-resistant (XDR) tuberculosis [6]. To overcome such challenges, the development of fast-acting chemotherapeutic agent is prerequisite.

Receptor-mediated targeting of a drug involves the specific transport of drug molecules to the infected macrophages utilizing receptor-mediated endocytosis pathway through cell surface receptor expressed on it such as transferrin receptor, scavenger receptor, tuftsin receptor etc [7-9]. Majumdar et al. conjugated $p$ aminosalicylic acid (PAS) to maleylated bovine serum albumin and enhanced the cellular uptake of drug 100 times by macrophages through scavenger receptor. The conjugate was 100 times effective as compared to free PAS in killing intracellular mycobacteria [10]. Horváti et al. used T-cell epitope of immunodominant $16 \mathrm{kDa}$ protein of M. tuberculosis and tuftsin-derived peptides as carrier molecules to conjugate isoniazid. They found that all INH conjugates were effective against $M t b$ [11]. Rashmirekha et al. synthesized a novel anti-TB drug complex consisting of zinc and rifampicin (ZnRIF) and encapsulated it into transferrin-conjugated silver quantum-dots (QDs) to improve delivery in macrophages. They showed transferrin (Tf) conjugated QDs constitute an effective drug 
delivery system for tuberculosis therapy [12]. The use of plasma protein transferrin as a carrier moiety is widely known for anticancer drug delivery. One can also introduce it in the delivery of antitubercular drug because of expression of transferrin receptor (TfR) on infected macrophages along with simple, reproducible and well characterized covalent conjugation of protein with the drug.

Human plasma transferrin is a nonheme iron-binding glycoprotein (molecular mass $80 \mathrm{kDa}$ ) [13]. The primary role of Tf is to control the levels of free iron in body fluids by binding, sequestering and transporting $\mathrm{Fe}^{3+}$ ions [14-16]. Mtb infects macrophages and survives on host iron. Mtb acquire iron from the host cell by synthesizing siderophores (carboxymycobactin \& mycobactin) and also from haem sources [17-19]. Besides, host iron carrier proteins Tf and lactoferrin are actively recruited by this pathogen to the phagosomal compartment for the acquisition of iron [20-23]. The TfR and specific receptor appear to be expressed on macrophages and mycobacteria for the binding of $\mathrm{Tf}$ on it [20]. A recent study shows that $M t b$ acquires iron from Tf by three mechanisms. The first is siderophores dependent withdrawal and intracellular delivery of iron. The second mechanism involves the delivery of iron using the high-affinity transporter IrtAB by a mycobactinindependent pathway. The third mechanism of transferrin-iron acquisition is independent of siderophores and consists of the internalization of transferrin by GAPDH receptor [24]. Thus expression of receptors, ability to internalize, and necessity of iron for the survival of mycobacteria make this protein an extensively accessible carrier for the receptor-mediated delivery of the drug into the infected macrophages.

The present work reports the synthesis of isoniazid-transferrin conjugates, its characterization and in vitro antimycobacterial activity. To the best of our knowledge, this is the first report on the conjugation of an antitubercular agent with human plasma protein transferrin. Our primary aim was to utilize simple and readily available linkers and to study its influence on Tf-INH conjugation.

\section{Materials and methods}

\subsection{Materials}

Transferrin (Holo) from human plasma ( $\geq 95 \%$, SDS-PAGE) purchased from Sigma Aldrich St. Louis, MO, USA). Isoniazid was obtained as a gift sample from Loba Chemie Ltd., glyoxylic acid monohydrate and glutaric anhydride, 2,4,6-trinitrobenzene 1sulfonic acid (TNBS), 1-Ethyl-3-[3-dimethylaminopropyl] carbodiimide hydrochloride (EDC), H-hydroxy succinimide (NHS), Sodium chloride, potassium dihydrogen phosphate $\left(\mathrm{KH}_{2} \mathrm{PO}_{4}\right)$, disodium hydrogen phosphate $\left(\mathrm{Na}_{2} \mathrm{HPO}_{4}\right)$, potassium bromide were purchased from Sigma Aldrich St. Louis, MO, USA. Acetonitrile, dimethyl sulphoxide (DMSO) were obtained from Merck.

\subsection{Synthesis of isonicotinoylhydrazonoacetic acid (IH) (2)}

The aqueous solution of glyoxylic acid monohydrate $(0.92 \mathrm{~g})$ was prepared and INH (1.37 g) dissolved in acetonitrile/water (1:4 v/v) was added to it. After completion of the reaction, the precipitate was filtered and washed with water and dried. The spectroscopic data is summarized in supporting information.

\subsection{Synthesis of isonicotinoylhydrazinyl-5-oxopentanoic acid(IG)(3)}

INH (1.37 g) was dissolved in acetonitrile/water $(1: 4 \mathrm{v} / \mathrm{v})$ and added to the aqueous solution of glutaric anhydride $(1.14 \mathrm{~g})$. After completion of the reaction, the precipitate was filtered and washed with water and dried. The spectroscopic data is summarized in supporting information.

\subsection{Conjugation of isonicotinoylhydrazonoacetic acid (4) and isonicotinoylhydrazinyl-5-oxopentanoic acid (5) to transferrin}

Conjugates of isonicotinoylhydrazonoacetic acid (IH) or isonicotinoylhydrazinyl-5-oxopentanoic acid (IG) with Tf at different molar ratios (Tf: IH/IG; 1:20,1:40,1:60,1:100) were prepared. IH/IG was added in PBS (pH 7.4) followed by EDC and NHS (1.5:3 mol). The solution was allowed to stir for $2 \mathrm{~h}$ for the activation of acid groups. After complete consumption of IH/IG, Tf [dissolved in PBS ( $\mathrm{pH}$ 7.4)] was added dropwise in the reaction mixture with stirring. The reaction was carried out for $12 \mathrm{~h}$ at $20^{\circ} \mathrm{C}$. The mixture was then dialyzed against deionized water at $4{ }^{\circ} \mathrm{C}$ for $48 \mathrm{~h}$ using a dialysis membrane (MWCO: 12-14 kDa) to remove salt, unreacted drug intermediates, and urea by-products. Finally, the product was lyophilized. The purity of synthesized forms of conjugates was determined using SDS-PAGE on $10 \%$ polyacrylamide gel at $120 \mathrm{~V}$. The samples were prepared under non-reducing condition. The staining of gel and visualization of bands was done with $0.25 \%$ Coomassie blue stain using Bio-Rad.

The available amino groups present on $\mathrm{Tf}$ before and after conjugation was determined by the 2,4,6-trinitrobenzene-1sulfonic acid (TNBS) reagent [25-27]. Briefly, an amount of $4 \mathrm{ml}$ of Tf or Tf conjugate $(0.25 \mathrm{mg} / \mathrm{ml})$ in the aqueous buffer of $0.1 \mathrm{~N}$ $\mathrm{NaHCO}_{3}$ (pH 8.3) was mixed with $2 \mathrm{ml}$ of $0.01 \%$ TNBS. The mixture was incubated at $37^{\circ} \mathrm{C}$ for $4 \mathrm{~h}$. Further, $1 \mathrm{ml}$ of $1 \mathrm{~N} \mathrm{HCl}$ and $2 \mathrm{ml}$ of $10 \%$ sodium dodecyl sulfate (SDS) were added to each sample and mixed. The absorbance of the sample was measured at $340 \mathrm{~nm}$ using a UV/Vis spectrophotometer (Shimadzu UV-2600). The calibration curve was plotted by using L-lysine as a standard (Fig. S4). The concentration of free primary amino groups on Tf and Tf conjugate was estimated from the calibration curve.

\subsection{UV-visible spectroscopy}

UV-visible spectrophotometric analysis of samples was performed for the confirmation of Tf-INH conjugation on UV-visible spectrophotometer (Shimadzu UV-2600) in a $1 \mathrm{~cm}$ cell. The absorbance spectra of INH, Tf, Tf-IG, and Tf-IH were measured in phosphate buffer solution ( $\mathrm{pH}$ 7.4), and absorbance maximum was measured.

\subsection{MALDI-TOF measurement}

Mass spectrometry (MS) was used to determine the molecular weight of prepared IG/IH-transferrin conjugate. The mass spectra of Tf and its conjugates were evaluated, and the difference between masses of both the compounds was used to determine the molar ratio of drug conjugated to a protein. Matrix-assisted laser desorption/ionization time of flight (MALDI-TOF) mass spectrometry (UltrafleXtreme ${ }^{\mathrm{TM}}$, Bruker Daltonics, Bremen, Germany) was used in a linear mode to determine the molecular weight of the compounds. The solutions of transferrin and transferrin conjugates were prepared at $10 \mu \mathrm{g} / \mathrm{ml}$ of concentration. A saturated solution of matrix-sinapic acid (SA) in 50\% acetonitrile and 0.05\% trifluoroacetic acid was prepared, and protein or conjugate was mixed into it in a volume ratio of $1: 1$. Further, $0.5 \mu \mathrm{l}$ of the sample was applied to a steel plate.

\subsection{In vitro antitubercular activity}

The antitubercular activity of INH, INH-H, INH-G, Tf-IH, and TfIG was determined using the Microplate Alamar Blue assay (MABA) [28]. MABA assay was performed in 96-well flat bottom plates. Mtb strains were cultured in 7H9-ADS medium and grown till the exponential phase $\left(\mathrm{OD}_{600}\right.$ of 0.6$)$. Approximately $1 \times 10^{5}$ bacteria 
were taken per well in a total volume of $200 \mu \mathrm{l}$ of the 7H9-ADS medium. Wells containing no Mtb were used for autofluorescence control. Additional controls consisted of wells containing cells and medium only. Plates were incubated for 5 days at $37^{\circ} \mathrm{C}, 30 \mu \mathrm{l}(0.02 \%$ wt/vol stock solution) Alamar Blue was added. Plates were reincubated for color transformation (blue to pink). Fluorescence intensity was measured in a SpectraMax M3 plate reader (Molecular Device) in a top-reading mode with excitation at $530 \mathrm{~nm}$ and emission at $590 \mathrm{~nm}$. Percentage inhibition was calculated based on the relative fluorescence units, and the minimum concentration that resulted in at least $90 \%$ inhibition was identified as MIC.

\subsection{In vitro cytotoxicity study}

The cytotoxicity of INH, Tf-IH, and Tf-IG was tested in THP-1 differentiated macrophages using MTT assay. Cells were allowed to adhere for $24 \mathrm{~h}$ in a 96 -well plate at a density of 3000 cells/well prior to the assay. Further, cells were exposed to various concentrations of $0.9 \%$ saline (the control), INH, Tf- $\mathrm{IH}$, and Tf-IG at various concentrations for $48 \mathrm{~h}$ at $37{ }^{\circ} \mathrm{C}$ and $5 \% \mathrm{CO}_{2}$ atmosphere, respectively. Culture medium was used as the blank group. After that, the MTT solution was added to each well and cells were incubated for $4 \mathrm{~h}$. To dissolve the MTT formazan crystals, $200 \mu \mathrm{l}$ of DMSO was added to each well. A microplate reader (Model 680, BIO-RAD, Hercules, CA) was used to measure the optical density of the formazan product at $570 \mathrm{~nm}$. The drug concentration causing $50 \%$ inhibition $\left(\mathrm{IC}_{50}\right)$ was calculated.

\subsection{Intracellular killing of Mtb}

20000 THP-1 cells in $100 \mu$ media (RPMI+ 10\% FBS) with $20 \mathrm{ng} /$ $\mathrm{ml}$ phorbol 12-myristate 13-acetate (PMA) per well were seeded in flat with adhesive 96 well plate. After that, the plate was incubated for $24 \mathrm{~h}$ in $5 \% \mathrm{CO}_{2}$ incubator. After $24 \mathrm{~h}$ of incubation cells were washed with PBS and added fresh media and further incubated for 24-48 h, and after incubation cell were infected with H37Rv at multiplicity of infection (MOI) (20000 THP-1: 40000 bacilli) and left for $4 \mathrm{~h}$, washed with PBS and were added fresh media with Amikacin $-0.2 \mathrm{mg} / \mathrm{ml}$ and incubated for $1 \mathrm{~h}$, after that 3 times washing were done and cells were incubated with appropriate concentration of drugs, and finally cells were plated at two time points for determining the colony forming unit (CFU), first at 0 days before treatment and second after $48 \mathrm{~h}$ [29].

\subsection{Stability study}

The stability of hydrazone and amide bond containing INH conjugates was analyzed by HPLC sampling over $24 \mathrm{~h}$. INH, Tf-IH/IG (T3) were dissolved in PBS 4.0 and PBS 7.4 separately at $0.5 \mathrm{mg} / \mathrm{ml}$ concentration. $20 \mu \mathrm{l}$ of sample was injected after $2,6,8,12,18,24 \mathrm{~h}$ to $250 \times 4.6 \mathrm{~mm}$ I.D., $5 \mu \mathrm{m}$ particle, Phenomenex Luna C18 column. Gradient elution mode was applied using acetonitrile (A) and $15 \mathrm{mmol} / \mathrm{L}$ potassium dihydrogen phosphate buffer of $\mathrm{pH}$ adjusted to $4.0 \pm 0.1$ with orthophosphoric acid (B) as a mobile phase (A:B ratio $50: 50 \mathrm{v} / \mathrm{v})$.

\subsection{Statistical analysis}

Cytotoxicity study and intracellular killing assay were performed in triplicate, and the results are expressed as mean \pm standard deviation (SD). Statistical analysis was done by performing Student's $t$-test. A value of $\mathrm{p}<0.05$ was considered significant $(\mathrm{n}=3)$.

\section{Result and discussion}

Transferrin was conjugated to isonicotinoylhydrazono acetic acid (IH) forming hydrazone linkage and to 5-(2sionicotinoylhydrazinyl)-5-oxopentanoic acid (IG) forming amide linkage using EDC-NHS coupling reaction. The - $\mathrm{COOH}$ groups of $\mathrm{IH}$ and IG were activated by EDC and NHS to react with primary amino groups of lysine of $\mathrm{Tf}$ (Scheme 1).

The SDS-PAGE shows the single dark prominent band at $\sim 79 \mathrm{kDa}$ for all Tf, Tf-IH and Tf-IG samples (Fig. 1.) The absence of any higher bands in SDS-PAGE confirms that there was no protein-protein coupling induced during the EDC-NHS coupling procedure. The absence of any smaller bands in the Tf conjugates in SDS-PAGE suggests there was no degradation of the Tf during the conjugation process.

The absorbance spectrum of free Tf, Tf-IH, Tf-IG, and INH dissolved in PBS pH 7.4 is given in Fig. 2. The free Tf showed an excitation wavelength at $279 \mathrm{~nm}$ while conjugated Tf shifts its wavelength at $274 \mathrm{~nm}$ indicating a blue shift and confirms the conjugation on $\mathrm{Tf}$

The concentration of surface lysine present in $\mathrm{Tf}$ before and after conjugation was determined by TNBS assay. The gradual decrease in the free amino group with the increase in the molar ratio of Tf$\mathrm{IH} / \mathrm{IG}$ confirms the covalent attachment of IH/IG (carboxyl group) to transferrin (amino group). The number of amino groups consumed on carrier Tf after conjugation is given in Table 1.

The further confirmation of conjugation was done by determining the mass to-charge ratio of Tf, and it's conjugate (S5-7). The molecular weight of Tf was found to be $78993.45 \mathrm{Da}$ (S5). The number of molecules of IH/IG per Tf molecule increases with the increase in the molar ratio of protein to the drug (Table 1). The changes in molecular weight were determined by observing the peak shift of the mass spectrum (S5-7). The molecular weight of free $\mathrm{IH}$ and free IG was 176.16 and 234.24 respectively. Based on the above findings, the approximate number of molecules of IH/IG per Tf molecule was calculated (Table 1). Moreover, the highest isoniazid density was seen at a molar ratio of 1:60 (T3) in both the conjugation systems. It was also observed that IH is more reactive than IG, as the number of molecules of IH conjugated to Tf was higher (Table 1).

The conjugates were also characterized by FTIR. An FTIR spectrum of IH, IG, Tf-IH, and Tf-IG is given in Fig. S1. The spectra of IH and IG showed broad $\mathrm{C}=\mathrm{O}$ stretch (carboxylic acid band) at $\sim 1720 \mathrm{~cm}^{-1}$ and $\mathrm{O}-\mathrm{H}$ stretch at $\sim 3334 \mathrm{~cm}^{-1}$. The peak at $1651 \mathrm{~cm}^{-1}$ indicates $\mathrm{C}=\mathrm{O}$ stretch of the amide. Spectra also showed $\mathrm{N}-\mathrm{H}$ bend of pyridine at $1440 \mathrm{~cm}^{-1}$. IG spectra showed $\mathrm{C}-\mathrm{H}$ (alkane) bend at $1465 \mathrm{~cm}^{-1}$ which is not present in IH spectra confirms the formation of isonicotinoylhydrazinyl-5-oxopentanoic acid. The spectra of Tf-IH and Tf-IG include the $\mathrm{C}=\mathrm{O}$ stretching at $1635 \mathrm{~cm}^{-1}$ in the amide I and $\mathrm{N}-\mathrm{H}$ deformation at $1537 \mathrm{~cm}^{-1}$ in amide II region which are characteristics of an intact $\alpha$ helix structure; indicate that the protein structure in the conjugates was intact. The peak at $1220 \mathrm{~cm}^{-1}$ corresponds to the $\mathrm{N}-\mathrm{N}$ bond in isoniazid which is not present in Tf spectrum. The $\mathrm{N}-\mathrm{H}$ bend of pyridine in Tf-IH/Tf-IG and $\mathrm{C}-\mathrm{H}$ stretch of alkane in Tf-IG shifted at $1395 \mathrm{~cm}^{-1}$ and $2840 \mathrm{~cm}^{-1}$ respectively because of conjugation.

\subsection{In vitro antitubercular activity}

The in vitro antimycobacterial activity of the INH, IH, IG, Tf-IH/IG (T3) was carried out by the determination of the $\mathrm{MIC}_{90}$ (the lowest concentration of the antibiotic at which $90 \%$ of the isolates was inhibited) using Mtb H37Rv strain. The MIC value of INH $(0.25 \mu \mathrm{g} /$ $\mathrm{ml}$ ) was found to be close to the literature value $(0.2-0.25 \mu \mathrm{g} / \mathrm{ml})$ [30-32] (Table 2). The derivatization of INH showed significant antimycobacterial activity $(6 \mu \mathrm{g} / \mathrm{ml})$. The MIC value of Tf-IH and Tf- 


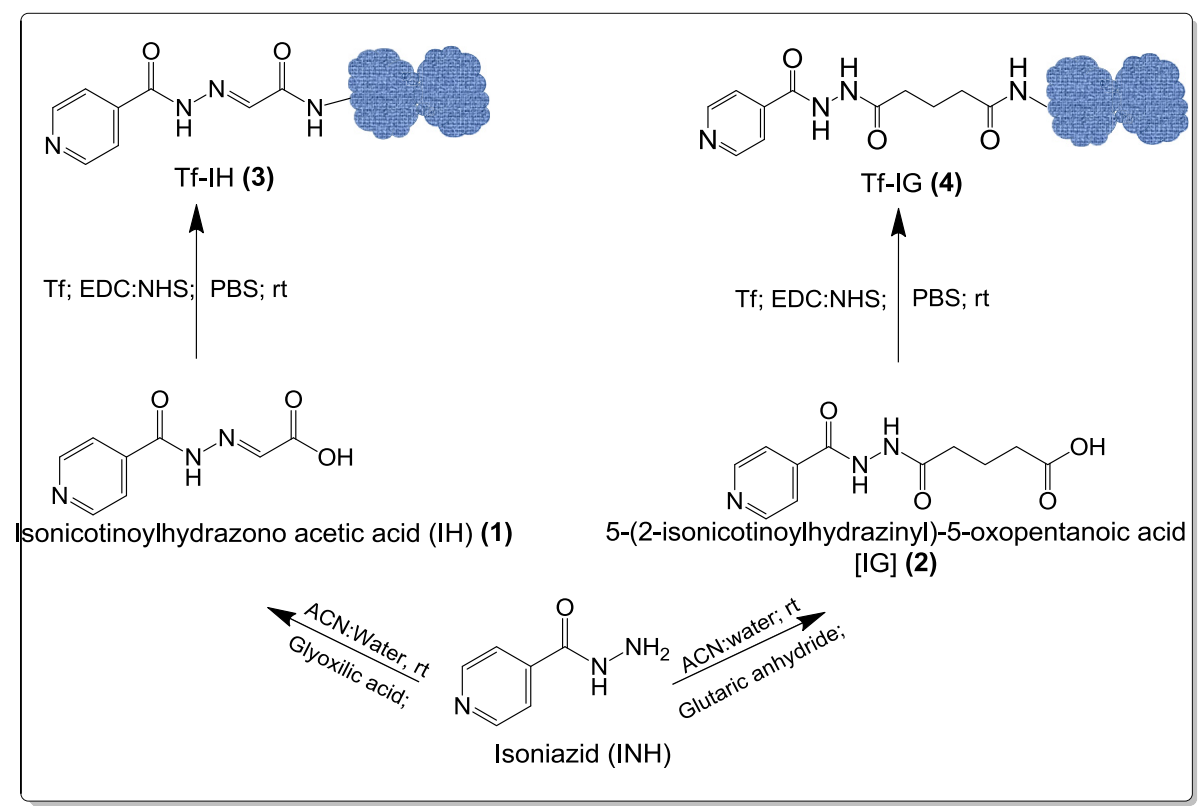

Scheme 1. Synthetic scheme for Tf-IH (3) and Tf-IG (4).

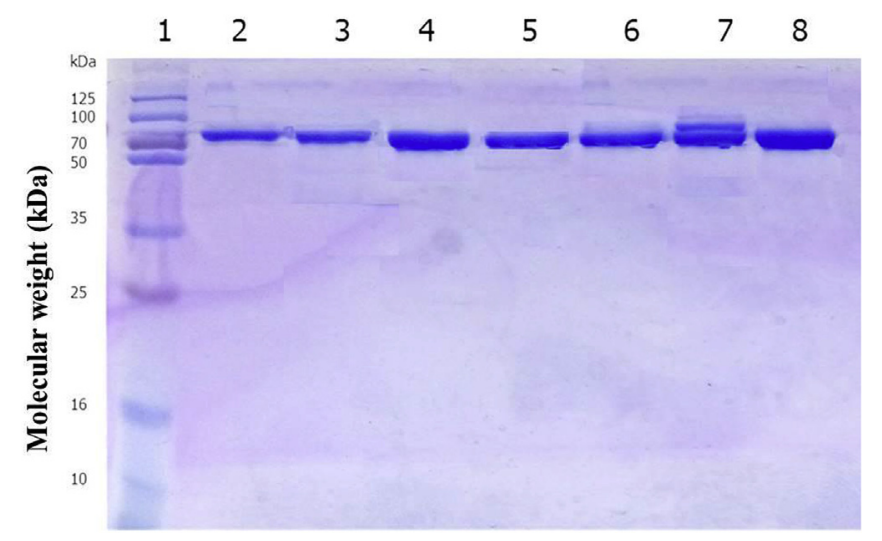

Fig. 1. SDS-PAGE of 1) Marker; 2) Tf; 3, 4, 5 \& 6) Tf-IH 1:20, 1:40, 1:60, 1:100 respectively; $7 \& 8$ ) Tf-IG $1: 40 \& 1: 60$ respectively. All samples are in $10 \mu \mathrm{l}$ concentration.

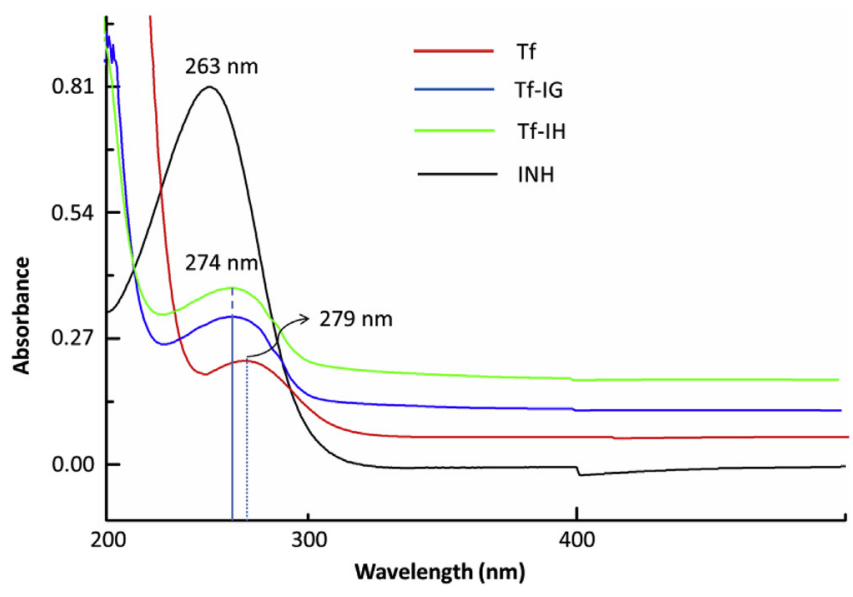

Fig. 2. UV-visible spectra of Tf, Tf-IG, Tf-IH, and INH.
IG conjugate was found to be $2.0 \mu \mathrm{g} / \mathrm{ml}$ and $4.0 \mu \mathrm{g} / \mathrm{ml}$ respectively (Table 2).

\subsection{In vitro cytotoxicity study}

From the therapeutic view, it is crucial that drugs should solely kill intracellular pathogen without displaying a cytotoxic effect on the host cell. In the present study, the cytotoxic study of prepared conjugates along with free drug was determined on THP-1 differentiated macrophages using MTT assay. It was found that the free drug and the synthesized conjugates had no cytotoxic effects on the THP-1 macrophages. (Table 2, Fig. 3).

\subsection{Intracellular killing of $M t b$}

INH and its synthesized conjugates were cytotoxic above $25 \mu \mathrm{g} /$ $\mathrm{ml}$ (Table 2). Hence to avoid false intracellular inhibition, the lowest concentration (MIC) $0.39 \mu \mathrm{g} / \mathrm{ml}$ was selected for further intracellular assay as at this concentration both $\mathrm{INH}$, and its conjugates showed cell viability (Fig. 4).

Cells were treated with free INH and conjugates (T3); free INH significantly reduced the colony forming unit (CFU) as compared to the untreated control cells (Fig. 4). While in the case of conjugates, further reduction in CFU was observed as compared to that of free INH. Tf-IG showed slightly higher CFU than Tf-IH, this result may be attributed to the number of bound INH molecules to the transferrin (Tf-IH > Tf-IG) present in both the conjugates.

Hence, it is proved that both Tf conjugates, Tf-IH, and Tf-IG meticulously inhibited the intracellular M. tuberculosis bacterial burden.

\subsection{Stability study}

The pH-dependent stability of INH conjugates (T3) in phosphate buffer solution ( $\mathrm{pH} 4.0$ and 7.4) were analyzed by RP-HPLC sampling over $24 \mathrm{~h}$. The results are summarized in Fig. 5. The Tf-IH conjugate was found to be stable up to $12 \mathrm{~h}$ at $\mathrm{pH}$ 4.0. However, a further increase in incubation time increased the percent release of INH. While at $\mathrm{pH} 7.4$, the release pattern was slow as compared to 
Table 1

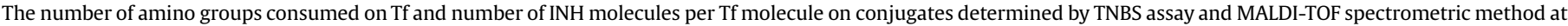
various Tf:IH/IG molar ratio.

\begin{tabular}{|c|c|c|c|c|c|c|c|}
\hline \multirow[t]{2}{*}{ Conjugate } & \multirow[t]{2}{*}{ Tf:IH/IG molar ratio } & \multicolumn{2}{|c|}{$\begin{array}{l}\text { Approximate no. of } \\
\text { amino groups } \\
\text { consumed on Tf }\end{array}$} & \multicolumn{2}{|c|}{ MALDI-TOF; Mass (Da) } & \multicolumn{2}{|c|}{$\begin{array}{l}\text { No. of INH molecules per Tf } \\
\text { molecule }\end{array}$} \\
\hline & & Tf-IH & Tf-IG & Tf-IH & Tf-IG & Tf-IH & Tf-IG \\
\hline Control & $1: 0$ & 0 & 0 & 78993.45 & 78993.45 & 0 & 0 \\
\hline $\mathrm{T} 1$ & $1: 20$ & 4 & - & 79502.55 & - & $2.89(3)$ & - \\
\hline $\mathrm{T} 2$ & $1: 40$ & 6 & 1 & 79914.77 & 79234.72 & $5.23(5)$ & $1.03(1)$ \\
\hline T3 & $1: 60$ & 8 & 2 & 80195.60 & 79323.80 & $6.82(7)$ & $1.41(1)$ \\
\hline $\mathrm{T} 4$ & $1: 100$ & 8 & 2 & 80194.80 & 79323.72 & $6.81(7)$ & $1.40(1)$ \\
\hline
\end{tabular}

(-) no significant change.

Table 2

In vitro antitubercular activity and cytotoxicity of INH, INH-H, INH-G and INHprotein conjugates.

\begin{tabular}{lll}
\hline Compound & $\mathrm{MIC}_{90}(\mu \mathrm{g} / \mathrm{ml})$ & $\mathrm{IC}_{50}{ }^{\mathrm{a}}(\mu \mathrm{g} / \mathrm{ml})^{\mathrm{b}}$ (4days) \\
\hline INH & 0.25 & $>25$ \\
INH-H & 6.0 & - \\
INH-G & 6.0 & - \\
Tf-IH & 2.0 & $>25$ \\
Tf-IG & 4.0 & $>25$ \\
\hline
\end{tabular}

a The half maximal inhibitory concentration $\left(\mathrm{IC}_{50}\right)$.

b MTT assay performed on THP-1 differentiated macrophages.

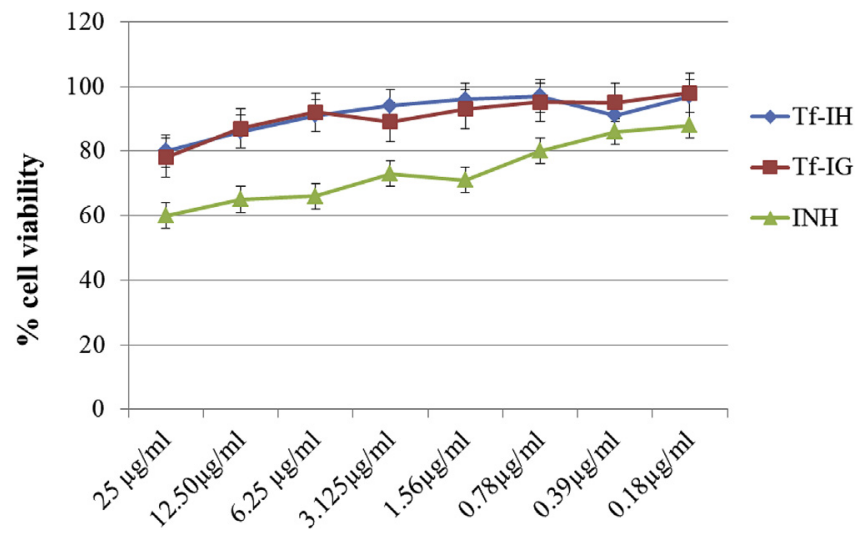

Fig. 3. Viability of THP- 1 cells differentiated to macrophages after $48 \mathrm{~h}$ of treatment with INH, Tf-IH, and Tf-IG at different concentration. Each point represents the mean \pm SD of triplicate measurements.

$\mathrm{pH}$ 4.0. It may be due to the hydrolysis of hydrazone conjugate which occurs fast in acidic $\mathrm{pH}$. In comparison with Tf-IH, less percent release of INH from Tf-IG was observed at both the $\mathrm{pH}$ even after $18 \mathrm{~h}$. Thus stability data reflects the $\mathrm{pH}$-dependent stability of both the linkers for a longer time.

Based on the above findings, it can be considered that Tf-INH conjugates take longer time to release the free drug. We can postulate the plausible mechanism for the cleavage of INH from the synthesized conjugates. Both the conjugates seem to be stable at blood $\mathrm{pH}(\mathrm{pH}$ 7.4) for a longer time, which is suggestive of the enhanced residence of conjugates in circulation. Tf-IH releases drug faster due to hydrolysis of hydrazone conjugate at acidic $\mathrm{pH} 4.0$ [33,34]. Thus after internalization of Tf conjugate in $M t b$ infected macrophage through Tf receptors, hydrazone linker may be cleaved in acidic endosome and lysosome via endocytosis, to trigger the release of INH. Tf-IG comparatively releases the drug slowly at $\mathrm{pH} 4.0$, may be due to more stable amide linkage. While it may be assumed that, amide linkage in Tf-IG conjugate may be cleaved by lysosomal protease enzyme to release the free INH moiety in the cytosol [35].

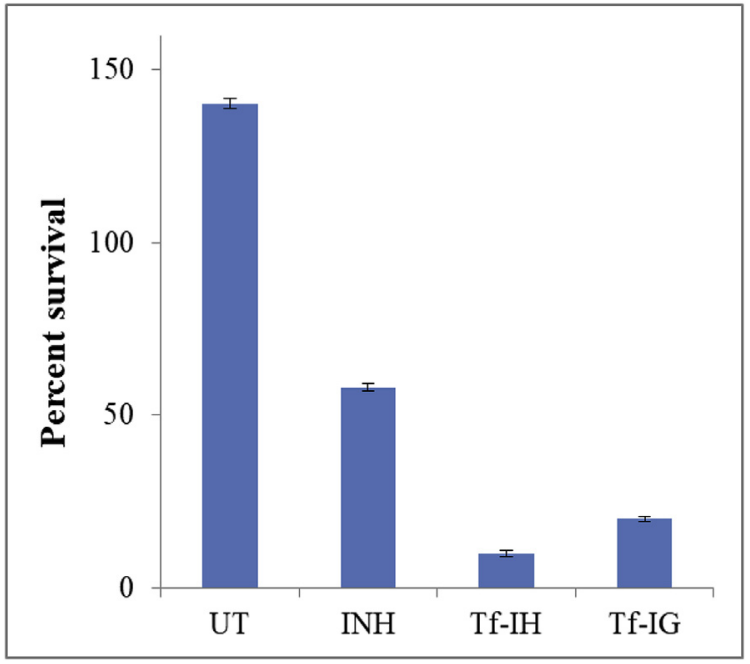

Fig. 4. Percent survival of intracellular Mtb (CFU) by INH, Tf-IH, and Tf-IG when THP-1 macrophages were infected with Mtb H37Rv and treated with compounds at $0.39 \mu \mathrm{g} /$ $\mathrm{ml}$ final concentration. UT: untreated. Values represent mean $\pm \mathrm{SD}, n=3$.

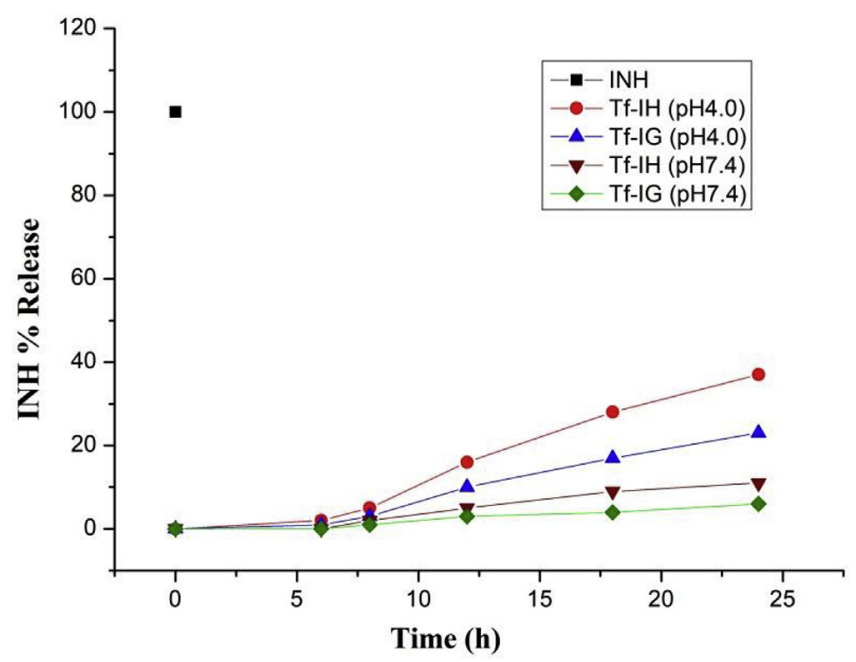

Fig. 5. Stability of INH conjugates as a function of time in PBS pH 4.0 and $\mathrm{pH} 7.4$

\section{Conclusion}

In summary, we have synthesized novel isoniazid-transferrin conjugates and examined the influence of chemical linkages (hydrazone and amide linkers) on its antitubercular potential. The study revealed that higher numbers of hydrazone intermediates 
were conjugated to the Tf suggesting that the hydrazone intermediate was more reactive towards amine functionality of Tf than that of amide intermediate. Both the conjugates showed significant antimycobacterial activity in comparison with free INH and have $\mathrm{pH}$ dependent stability. While in the case of ex vivo study on infected THP- 1 cells, Tf-IH showed a substantial decrease in CFU at $0.39 \mu \mathrm{g} / \mathrm{ml}$ concentration in comparison with Tf-IG and free INH. Hence, we can conclude that the conjugation of antitubercular agents to human plasma protein based carrier (Transferrin) is a promising approach to improve the efficacy and potency of a drug. Further, in-depth ex vivo and in vivo studies to identify the Mtb targeting efficiency of this novel conjugates and establishment of its delivery system are underway which will be communicated in the future.

\section{Author contribution}

All authors contributed equally.

\section{Acknowledgments}

We acknowledge University Grants Commission-Basic Scientific Research (UGC-BSR), New Delhi, India for the financial support of this work. We also acknowledge DBT-IISc partnership Program for funding and supporting Biosafety level-3 facility for Mtb work at IISc, Bangalore, India. We thank Biosciences \& Bioengineering, IIT Bombay for performing MALDI-TOF of protein and its conjugates. We also thank National Facility for Biopharmaceutical, Mumbai for performing SDS-PAGE.

\section{Appendix A. Supplementary data}

Supplementary data to this article can be found online at https://doi.org/10.1016/j.ejmech.2019.111713.

\section{Abbreviations}

$\begin{array}{ll}\text { Mtb } & \text { Mycobacterium tuberculosis } \\ \text { TB } & \text { tuberculosis } \\ \text { Tf } & \text { transferrin } \\ \text { MDR } & \text { multidrug resistant } \\ \text { XDR } & \text { extensively drug-resistant } \\ \text { HIV } & \text { human immunodeficiency virus } \\ \text { PAS } & \text { p-aminosalicylic acid } \\ \text { QD } & \text { quantum dots } \\ \text { TfR } & \text { transferrin receptor } \\ \text { kDa } & \text { kiloDalton } \\ \text { SDS-PAGE } & \text { sodium dodecyl sulfate-polyacrylamide gel } \\ & \text { electrophoresis } \\ \text { EDC.HCl } & \text { 1-ethyl-3-(3-dimethylaminopropyl)carbodiimide } \\ & \text { hydrochloride } \\ \text { NHS } & \text { N-hydroxy succinimide } \\ \text { ACN } & \text { acetonitrile } \\ \text { MALDI-TOF Matrix-assisted laser desorption/ionization time of } & \text { flight } \\ \text { PBS } & \text { phosphate buffer solution } \\ \text { MIC } & \text { lowest concentration of drug that inhibits growth of } \\ & \text { more than 90\% of the bacterial population } \\ \text { IC } & \text { lowest concentration of drug that inhibits growth of } \\ & \text { more than 50\% of the cell population }\end{array}$

\section{References}

[1] WHO, Global Tuberculosis Report 2018, 2018.

[2] G. Evelyn, S.S. Larry, K. Gilla, Macrophages in tuberculosis: friend or foe,
Semin. Immunopathol. 35 (2014) 563-583.

[3] P. Jean, Mycobacterium tuberculosis and macrophage: maintaining a balance, Cell Host Microbe 3 (2008) 399-407.

[4] B.R. Willium, T.R. Hawn, Mycobacterium tuberculosis, macrophages, and the innate immune response: does common variation matters? Immunol. Rev. 219 (2007) 167-186.

[5] N.,M. Mohammad, K.N. Md, D. Shilpi, Nanotechnology-based approach in tuberculosis treatment, Tuberc. Res. Treat. 1-12 (2017).

[6] G. Gunar, Multidrug-resistant and extensively drug-resistant tuberculosis: a review of current concepts and future challenges, Clin. Med. 14 (2014) 279-285.

[7] P.R. Taylor, L. Martinez-Pomares, M. Stacey, H.-H. Lin, G.D. Brown, S. Gordon, Macrophage receptors and immune recognition, Annu. Rev. Immunol. 23 (2005) 901-944.

[8] R.B. John, J.V. Stefaan, A. Rui, R.G. Victor, The effect of the host's iron status on tuberculosis, J. Infect. Dis. 195 (2007) 1745-1753.

[9] K. Mounty, Structures and functions of multiligand lipoprotein receptors: macrophage scavenger receptors and ldl receptor-related protein (LRP), Annu. Rev. Biochem. 63 (1) (1994) 601-637.

[10] M. Sadhana, K.B. Sandip, Killing of intracellular mycobacterium tuberculosis by receptor-mediated drug delivery, Antimicrob. Agents Chemother. 35 (1) (1991) 135-140.

[11] H. Kata, M. Gábor, S. Nóra, H. Ferenc, B. Szilvia, Peptide conjugates of therapeutically used antitubercular isoniazid-design, synthesis and antimycobacterial effect, J. Pept. Sci. 15 (5) (2009) 385-391.

[12] P. Rashmirekha, S. Rojalin, P. Jagannath, S. Avinash, Encapsulation of zincrifampicin complex into transferrin-conjugated silver quantum-dots improves its antimycobacterial activity and stability and facilitates drug delivery into macrophages, Sci. Rep. 6 (2016) 1-14.

[13] G. Konstantinos, P. George, P. Kostas, Regulation of iron transport and the role of transferrin, Biochim. Biophys. Acta 1820 (3) (2012) 188-202.

[14] P. Jaakko, V.B. Leni, E. Freja, S. Leila, Function and therapeutic development of apotransferrin, Vox Sanguinis 83 (1) (2002) 321-326.

[15] T.A.M. Ross, A.M. Stanley, C. Jie, F.A. Bryan, B. Heather, L. Yaoguang, B. Maria A.S. Clyde, E.P.M. Michael, W. Yili, B.M. Anne, C.W. Robert, D.B. Gary, N.B. Edward, Two high-resolution crystal structures of the recombinant nlobe of human transferrin reveal a structural change implicated in iron release , Biochemistry 37 (22) (1998) 7919-7928.

[16] H. Masaaki, The structural mechanism for iron uptake and release by transferrins, Biosci. Biotechnol. Biochem. 64 (2000) 1328-1336.

[17] B. Sharmistha, F. Aisha, Z.E. Nasreen, E.H. Seyed, Iron acquisition, assimilation and regulation in mycobacteria, Infect. Genet. Evol. 11 (5) (2011) 825-838.

[18] R. Colin, Iron, mycobacteria and tuberculosis, Tuberculosis 84 (2004) $110-130$.

[19] J.D.V. James, R. Kerry, G.S. Benjamin, E.B. Clifron, Iron acquisition and metabolism by mycobacteria, J. Bacteriol. 181 (1999) 4443-4451.

[20] W. Dirk, M. Jorg, L. Barry, C. Zhonghou, E.B. Clifton, H.z.B. Kerstin, G.R. David, E.B. Luiz, Elemental analysis of mycobacterium avium-, mycobacterium tuberculosis-, and mycobacterium smegmatis-containing phagosomes indicates pathogen-induced microenvironments within the host cell's endosomal system, J. Immunol. 174 (3) (2005) 1491-1500.

[21] L. Daniel, A.H. Marcus, The mycobacterium tuberculosis phagosome interacts with early endosomes and is accessible to exogenously administered transferrin, J. Exp. Med. 184 (4) (1996) 1349-1355.

[22] O. Oyebode, S.S. Larry, A. Ambar, E.B. Bradley, Intraphagosomal mycobacterium tuberculosis acquires iron from both extracellular transferrin and intracellular iron pools: impact of interferon- $\gamma$ and hemochromatosis, J. Biol. Chem. 277 (51) (2002) 49727-49734.

[23] O. Oyebode, S.S. Larry, A. Ambar, E.B. Bradley, The nature of extracellular iron influences iron acquisition by mycobacterium tuberculosis residing within human macrophages, Infect. Immun. 72 (4) (2004) 2022-2028.

[24] M.B. Vishant, M. Himanshu, S.T. Janak, A.T. Vikas, V. Bhavana, P. Pravinkumar, S. Navdeep, S. Prerna, S.C. Anoop, R. Manoj, I.R. Chaaya, Mycobacterium tuberculosis acquires iron by cell-surface sequestration and internalization of human holo-transferrin, Nat. Commun. 5 (2014) 4730.

[25] M.L. Kyung, S.K. In, B.L. Yong, C.S. Sang, C.L. Kang, J.O. In, Evaluation of Transferrin-Polyethylenimine conjugate for targeted gene delivery, Arch Pharm. Res. (Seoul) 28 (6) (2005) 722-729.

[26] K.V. Singh, J. Kaur, G.C. Varshney, M. Raje, C.R. Suri, Synthesis and characterization of hapten-protein conjugates for antibody production against small molecules, Bioconjug. Chem. 15 (1) (2004) 168-173.

[27] H.A. Hardik, M.M. Nilesh, P. Chulhun, H.N. Van, T.T. Thao, H.T. Phuong, L. Beom, Fattigation-platform nanoparticels using apo-transferrin stearic acid as a core for receptor-oriented cancer targeting, Colloids Surfaces B Biointerfaces 159 (2017) 571-579.

[28] M. Archita, S.M. Ashalatha, S.R. Raju, R. Ananya, R. Rajanya, S. Avadhesha, An allosteric inhibitor of mycobacterium tuberculosis argj: implications to a novel combinatorial therapy, EMBO Mol. Med. 10 (4) (2018) 1-21.

[29] M. Saurabh, S. Prashant, B. Ashima, A. Kushi, B. Priyanka, J. Rajiv Kumar M. Abhilash, S.R. Raju, N. Valakunja, C. Nagasuma, S. Amit, Efficacy of $\beta$-Lac$\operatorname{tam} / \beta$-Lactamase inhibitor combination is linked to WhiB4-mediated changes in redox physiology of Mycobacterium Tuberculosis, eLife 6 (2017) 1-30.

[30] L. Vahid, Malihe, Z.B. Abed, F. Lanfranco, D. Michel, H. Mohsen, D.-S. Davood, Trends in the discovery of new drugs for mycobacterium tuberculosis therapy with a glance at resistance, Tuberculosis 109 (2018) 17-27. 
[31] G.V. Suresh Kumar, Y. Rajendra Prasad, B.P. Mallikarjuna, S.M. Chandrashekar, Synthesis and pharmacological evaluation of clubbed isopropylthiazole derived triazolothiadiazoles, triazolothiadiazines and mannich bases as potential antimicrobial and antitubercular agents, Eur. J. Med. Chem. 45 (11) (2010) 5120-5129.

[32] B. Sanjib, S. Nicolo, M. Arundhati, K.B. Alistair, D. Saiprasad, E. Dimitrios, D.M. Timothy, N.M. Parisa, T. Alexander, P. Elena, M. Fabrizio, C. Daniele Design and synthesis of 1-((1,5-Bis(4-chlorophenyl)-2-methyl-1H-pyrrol-3yl)methyl)-4-methylpiperazine (BM212) and N-Adamantan-2-yl-n'-((E)-3,7dimethylocta-2,6-dienyl)ethane-1,2-diamine (SQ109) pyrrole hybrid derivatives: discovery of potent antitubercular agents effective against multidrug-resistant mycobacteria, J. Med. Chem. 59 (6) (2016) 2780-2793.
[33] T. Kyoji, A. Zhiqiang, Antibody-drug conjugates: recent advances in conjugation and linker chemistries, Protein Cell 9 (1) (2018) 33-46.

[34] M. Sanjeev, T. Man-Wah, Antibody-antibiotic conjugates: a novel therapeutic platform against bacterial infections, Trends Mol. Med. 23 (2) (2017) 135-149.

[35] W. BinQing, G.-T. Janet, Y. Hui, W. Tao, X. Zijin, C. Jinhua, W. John, N. Jim, P.T. Siao, C. Josefa, R.K. Katherine, L. Yichin, Y. Shang-Fan, L. Jeff, L. Guangmin, D.P. Gail, L. Doug, K. Amrita, S. Dian, X. Keyang, E. Charles, S. Stefan, O. Rachana, R. Helga, R.S. Leanna, Z. Guiling, A.F. John, H.P. Thomas, V. Vishal, A.M. Luke, W.H. Philip, S. Brian, Discovery of peptidomimetic antibody-drug conjugate linkers with enhanced protease specificity, J. Med. Chem. 61 (2018) 989-1000. 